\title{
Sociopatología de la xenofobia y de los nacionalismos
}

\author{
Francesc Tort i Chavarría
}

Universitat Autònoma de Barcelona, Facultat de Ciències Polítiques

Departament de Sociologia. 08193 Bellaterra (Barcelona). Spain

\section{Resumen}

La enriquecedora comunicación intercultural que en principio debería esperarse de la convivencia en un mismo territorio de un sistema plural de normas y modelos de comportamiento aparece, no obstante, en muchas ocasiones, como uno de los problemas más característicos del proceso migratorio cuando, generalmente en situaciones de crisis económica y ambiente social de intolerancia, los extranjeros son percibidos como una anenaza a intereses o identidades, creándose así barreras para su integración y los consiguientes sentimientos mutuos de desconfianza y rechazo que se derivan.

El análisis de todo el proceso de representación negativa del "otro", con los correspondientes prejuicios étnicos y culturales que se esconden tras la manifiesta segregación social de las minorias inmigradas, ha conducido al autor del artículo a plantear el tema de la identidad personal y colectiva (étnica, religiosa o nacional) como central de cara a una mejor comprensión de uno de los aspectos más complejos y relevantes del fenómeno de la inmigración exterior en Cataluña.

Entiende el concepto de identidad como sinónimo de estructura psicosocial que orienta y vincula la actividad de la persona. Equivale a una relación ambivalente de inclusiónexclusión que situa al individuo en una lógica de pertenencia a unos grupos percibidos como propios, al tiempo que lo diferencia de otros grupos "ajenos", que serán tan extraños como la distancia social marcada por las condiciones históricas, políticas y económicas determine.

La xenofobia contempla numerosas genealogías simbólicas que van desde el ámbito de la categorización estereotipada del otro hasta una cierta definición de las identidades colectivas, que se suele traducir en una conciencia esencialista de pertenencia. Establece así una ana logía entre el sentimiento xenófobo y el nacionalista en tanto que expresiones de un tipo de comunicación intergrupal maniftesta o potencialmente excluyente, basada sobre todo en una politización de las identidades culturales y en la creación de fronteras reales o simbólicas.

Palabras clave: identidad, alteridad, categorización social, estereotipo, prejuicio.

\section{Abstract. Xenophoby and nationalisms' saciopathology}

The article deals with the process of representation of the wother». which is negative as far as it is influenced by ethnic and cultural prejudices. The problem of personal and collective identity is presented here as synonimous of a psycho and social structure which gives 
sense to a person's life. It implies a inclusion-exclusion relationship. Xenophoby is also related to symbolic representations. The analogy between the xenophobic and nationalistic sentiments is also discussed in deprh as the expression of an interpersonal type of communication.

Key words: identity, alterity, social category of migrant, stereotype, prejudice.

\section{Sumario}

1. Introducción

3. Relación entre xenofobia y nacionalismo

2. El papel de la identidad en la producción del extranjero

\section{Introducción}

El presente artículo tiene por objeto transmitirles algunas consideraciones téricas, hipótesis y reflexiones planteadas a lo largo de un estudio sociológico que acrualmente estoy realizando ${ }^{1}$ para tratar de establecer, entre otras cosas, la eventual relación de ciertas actitudes xenofobicas con un determinado sentimiento nacionalista que pudiera operar como potencial caldo de cultivo de las mismas.

Me parece interesante analizar las vinculaciones entre ambos fenómenos en la medida en que parecen compartir algunas bases y síntomas comunes, así como claras analogías en muchos aspecros, por ejemplo, desde el ámbito de la categorización del otro y la definición de identidades hasta una similar genealogía simbólica que les permite marcar en mayor o menor grado las vías de la integración o de la exclusión social.

Por otro lado, abordar el problema de la xenofobia y el nacionalismo significa también, a mi juicio, intentar comprender de qué forma se crea en algún imaginario colectivo una especial producción negativa del otro, del extranjero percibido como el no perteneciente al propio grupo. En este sentido, a través de determinadas relaciones físicas o rituales de adhesion, separación y distanciación, se instituyen una serie de jerarquizaciones de tipo étnico, cultural o político, cuya función es asegurar a los individuos una posición distintiva en el juego de las representaciones propias de cada contexto social.

Por otra parte, estimo que los estereotipos y los prejuicios aparecen en cuanto ese ser diferente, ajeno al propio grtspo, empieza a percibirse como un agente real o potencial de crisis, de amenazas a intereses e identidades provocando, a su vez, recelos, desconfianza o diferentes grados de aversión xenófoba.

1. Metodológicamente dicho trabajo parte del análisis de contenido de una serie de entrevistas en profundidad efectuadas a distintos representantes de instituciones públicas y privadas, vinculadas directa o indirectamente con el mundo de la inmigración extracomunitarja en Barcelona. 
La primera hipótesis de la exposición sería, pues, que en todo discurso xen 6 fobo y nacionalista subyace el binomio alteridad-identidad como fundamento constitutivo del mismo. Asimismo puede ayudar a comprender mejor la naturaleza del tema el relacionar una especial visión del extranjero por parte de cualquier grupo o comunidad con su búsqueda y afirmación de la identidad sociocultural, proceso que pasa inevitablemente por asignar al diferente un papel determinado en función del contexto histórico, político y económico por el que se atraviese.

\section{El papel de la identidad en la producción del extranjero}

Todo el complejo proceso de construcción social del otro, de la variada gama de imágenes del extranjero, constituye a mi entender una de las piezas básicas de los mecanismos de identificación colectiva de toda comunidad étnica o nacional. Desde esta perspectiva, entiendo por igual la xenofobia y el nacionalismo como expresiones de diversas formas de comunicación con ese distinto (con el extraño, con el que no se nos parece y no nos identificamos en una lógica social donde se trata tanto de identificarse como de distinguirse) basadas en la distancia autoafirmadora, en la estigmatización y en la creación de fronteras simbólicas tendentes a preservar las propias señas de identidad.

De hecho, la persona (que en su origen etimológico griego significa máscara) se podría definir como un ser en busca de su identidad. De manera que toda la conducta del individuo está encaminada al reconocimiento de la propia identidad con objeto de conseguir equilibrio psiquico y estabilidad emocional. Todo lo que refuerce la identidad personal contribuye a aumentar la sensación de seguridad, y una buena forma de conseguirlo consiste en el reforzamiento de los lazos de afiliación interpersonales basados más en la pertenencia afectiva al clan que en la participación libre y racional en cualquier instancia. El psiquiatra cordobes Carlos Castilla del Pino en su teoría del self ${ }^{2}$ apunta lo siguiente:

Se puede decir que todas las relaciones que un sujeto mantiene pretenden el logro y/o el mantenimiento de una identidad segura o, lo que es lo mismo, de Ia autoestima. En este sentido son importantes las actitudes que mantienten los demás respecto del self que el sujero propone que, básicamente, pueden ser de aceptación, rechazo o descalificacion. Peto son asimismo muy relevantes las actitudes que adopta el sujeto hacia su propio self [...]. Para conseguir el equilibrio de su self, es decir, para evitar su cuestionamiento y mantener la autoestima, el sujeto cuenta con los denominados mecanismos de defensa (represión, racionalización, sublimación, etc.). Por otra parte, mediante la fantasía y los sueños, en virtud de la omnipotencia del deseo que a estas formaciones caracteriza, se compensan las frustraciones - las heridas a la autoestima - que entraña la adecuación de la conducta a la realidad.

2. (Com.) Teorla del personaje (El capitulo "La construcción del selfy la sobreconstrucción del personajen es de Carlos Castilla del Pino). Madrid: Alianza, 1989, p. 45. 
En las definiciones de la identidad que encontramos en psicología social ${ }^{3}$ se suele hacer notar la dicotomía existente entre la identidad personal y la identidad social como reflejo del conflicto entre lo individual y lo colectivo o, en términos psicoanalíticos, entre el principio del placer y el de la realidad.

De hecho, se parte de la idea según la cual toda persona se caracterizaría por distintos atributos de orden social que marcan su pertenencia a grupos o categorías y por atributos específicos de orden personal. Así, la identidad social remite a lo que el individuo tiene de similar con otros individuos por el hecho de compartir con ellos una misma pertenencia a un grupo; pero también a una diferencia respecto a los miembros de otros grupos o categorías. Por su lado, la identidad personal vendría a indicar el reconocimiento que un individuo tiene de su diferencia en relación al prójimo.

En otras palabras, la identidad social concierne al sentimiento de similitud hacia los otros del propio grupo, mientras que la identidad personal descansa en el sentimiento de diferencia respecto a los de «afuera». En principio la presencia simultánea de similitud y de diferencia es, como mínimo, problemática, puesto que es difícil concebir que un individuo pueda ser igual y diferente a la vez.

Para resolver esta contradicción aparente, se han desarroliado básicamente dos modelos. El primero se basaría en el principio del todo o nada, según el cual las dos lógicas, la de la analogía y la diferencia, son mutuamente excluyentes. En el marco del segundo modelo, las diferenciaciones intergrupales e interindividuales no tienen porque situarse en los dos extremos de un continuum, sino que los sentimientos de similitud y de diferencia pueden ser vividos simultáneamente y de forma equilibrada en la representación del individuo. A escala social tal síntesis comportaría la plena aceptación de las diferencias culturales como un factor enriquecedor en una sociedad multiétnica y pluricultural.

Entendiendo, por tanto, el concepto de identidad como sinónimo de relación de pertenencia de un individuo a un grupo o comunidad percibidos como propios, el problema que se deriva de la crisis de un sentimiento de identidad no resuel to puede llegar a ser más importante de lo que normalmente se cree, debido a la profunda necesidad que tiene el hombre de una estructura que oriente y vincule su actividad y, a la postre, que dé sentido a su vida. Así lo señala Erich Fromm ${ }^{4}$ :

La necesidad de experimentar un sentimiento de identidad nace de la condicín misma de la existencia humana y es fuente de los impulsos más intensos. Puesto que no puedo estar sano sin el sentimiento del kyo", me siento impulsado a hacer casi cualquier cosa para adquirirlo.[...] ¿Hay algo más evidente que el hecho de que los individuos arriesgan sus vidas, renuncian al amor, renuncian a la libertad, sacrifican sus ideas para sentirse uno más del rebaño e

3. Una breve descripción de las mismas se puede encontrar en la revista Interculrures" "Préjugés, stéréotypes, reptésentations", núm.14, julio 1991.

4. Fromm, E. (1956). Psicoanálisis de la sociedad contemporánea. Madrid: Fondo de Cultura Económica, p. 59. 
identificado con el, con lo que adquieren un sentimiento de identidad, aunque sea una identidad ilusoria?

El hombre contemporáneo ha podido llegar a una fase de emergencia de la razón práctica y de la individualidad a través de la sucesiva ruptura de vínculos de índole esencialista que siempre lo habian unido de modo natural a diversas instancias comunitarias (familia, estamento, gremio, iglesia, etc.) cuyas normas regian su vida prevaleciendo sobre las estrictamente privadas. Con la llegada de la modernidad' la persona puede alcanzar mayores cotas de libertad a costa de la pérdida de la seguridad que le otorgaban esos lazos comunitarios propios de un mundo tradicional. Mediante la emancipación de los lazos de sangre y suelo, del padre y la madre, de fidelidades indiscutidas a etnias, clanes y religiones se sientan las bases para que, al menos en potencia, se consiga la plena independencia y autorrealización. La búsqueda del interés propio se erige, pues, en norma suprema de la vida aunque suela venir acompañada de muchas dudas acerca de cuál pueda ser nuestro auténtico yo y lo que más nos conviene. Si no se encuentra un propósito claro en lo que se hace unido a una incertidumbre en lo que se es y lo que se quiere a causa, por ejemplo, de una deficiente integración en los esquemas dominantes de la sociedad, se puede abrir un proceso de crisis anómica en términos de $\mathrm{E}$. Durkheim equiparable al célebre miedo a la libertad de E. Fromm, cuyo intento de alivio puede conducir a formas de relación basadas en la dependencia, bien sea de dominio o de sumisión.

Así, de la mano de este mismo autor podemos empezar a vislumbrar los fundamentos psicosociologicos de la xenofobia muy característicos de las personas con rasgos de carácter predominantemente autoritario. Veamos:

Para nuestra finalidad bastará decir ahora que el carácter autoritario es la estructura caracterológica de una persona cuyo sentido de fuerza e identidad se basa en una subordiración simbiótica a las autoridades, y al mismo tiempo en una dominación simbiótica de los sometidos a su autoridad. Ello equivale a decir que la persona autoritaria se siente fuerce cuando se puede someter y ser parte de una autoridad que (hasta cierto punto respaldada por la realidad) es inflada y endiosada, y cuando al mismo tiempo tal persona puede hincharse incor-

5. La sacióloga Cristina Peña-Marin señala lo siguiente en torno al papel de la identidad para el individuo moderno en un capitulo titulado "Del amor y los desórdenes de la idenridad", que forma parte del libro Filosofia y sexualidad (edición a cargo de Fernando Savater). Barcelona: Anagrama, 1988, p. 129:

"La identidad no le es dada al hombre moderno. Anres bien, hallarla será un asunto central de su existencia. Le están abiertas múltiples posibilidades de ser conforme a órdenes de significados muy distintos, al tiempo que cada opción que realice, la actitud que adopze en sus relaciones, exc. perfila los rasgos que le definen para los otros y para sí. Pero las definiciones de una misma persona son tan heterogéneas como los mundos en que las realiza. Por ello, cómo sea él mismo, en cuanto mismo, persistente en sus diferentes momentos, es una cuestión indecible que le somete a crisis más o menos radicales cuando la identidad proyectada en una situación resulta desmentida o no se ensambla con la representación contigua y el sujero cae en el vaclo entre dos imágenes de sín.

6. Fromm, E. (1986). La condición bumana actual Barcelona: Paidós Studio, p. 58. 
porando a aquellos sometidos a su autoridad. Trátase de un estado de simbiosis sadomasoquista que le proporciona un sentimiento de fuerza y un sentimiento de identidad.

Creo que, aparte de síntoma de una relación patológica con el otro, la xenofobia es una clara expresión de inseguridad que se proyecta sobre el chivo expiatorio de turno, tanto más rechazado cuanto más débil y ajeno se le considere. Una típica medida precautoria del grupo receloso será, por ejemplo, intentar conjurar ese miedo etiquetando y estigmatizando al forastero atribuyéndole una serie de presuntos rasgos negativos que afectan a todo el colectivo. De este modo se crean nuevas fronteras interiores tendentes a neutralizar sobretodo aquellos símbolos extraños que supuestamente no encajan con la propia realidad cultural ${ }^{7}$.

\section{Relación entre xenofobia y nacionalismo}

También desde esta perspectiva la nación vendría a ser una modalidad especial de agrupación humana basada en ciertos factores objetivos, pero fundamentalmente en sentimientos políticos de afiliación y de exclusión que son su principal elemento constitutivo. En este sentido el nacionalismo sería, pues, una determinada manifestación cultural que confiere identidad a algunos pueblos. De manera que esta factoría de mitos que es la cultura genera, a veces, conciencias nacionales cuya función principal es mantener una experiencia simbólica compartida y otorgar ese sentido de pertenencia y amparo vitales tan necesarios para la supervivencia individual y grupal. Normalmente este sentimiento nacionalista se instituye a partir de la afirmación frente a otra identidad nacional rival de la cual es preciso diferenciarse con objeto de reforzar las propias señas o lograr autoafirmaciones más efectivas.

En parecidos términos la xenofobia es ese sentimiento de inquietante extraneza hacia el diferente (hacia aquel que no pertenece al grupo nosotros y conviene distinguirse de él), ese movimiento personal interior que no se traduce necesariamente en un comportamiento violento ${ }^{8}$, sino habitualmente en forma

7. El paradigma de grupo social estigmatizado serían los gitanos. En un estudio del antropologo Tomás Calvo Buezas (iEspaña racista? Voces payas sobre los gitanos. Barcelona: Anthropos, 1990), según una encuesta realizada a profesores y alumnos de BUP de toda España, se llega a la conclusión de que los principales destinatarios de sus prejuicios raciales son los gitanos, por delante de colectivos inmigrantes como los magæebíes, negroafricanos, asiáticos y latinoamercanos. Desde hace 500 años son nuestros vecinos más próximos y quizás por ello más odiados para conjurar el miedo o la desconfranza que se les tiene. Habría que ver cómo ambos grupos crean sus estereotipos constituyéndose mútuamente en términos de alteridad radical como los extranjeros por excelencia.

8. Alain Finkielkraut en su libro La sabiduria del amor (México: Gedisa, 1988, p. 121) hace la siguiente interesante observación acerca de la verdadera naturaleza de la xenofobia:

"Antes que ser intolerancia a la diversidad, el odio al otro hombre (del cual el antisemirismo suministra el modelo) manifiesta la intolerancia del yo frente a su propia responsabilidads. 
de opinión, prejuicio o conductas de evitación, discriminación o rechazo. Freud nos habla de la misma con las siguientes palabras?:

(Este fenómeno) yo lo he llamado «narcisismo de las pequeñas diferenciasm.[...] Se constata una satisfaccion comoda y relativamente inofensiva del instinto agresivo, por lo cual la cohesión de la comunidad es más fácil para sus miembros. Desde este punto de vista, debido a su diseminación por doquier, el pueblo judio ha servido dignamente a la civilización de los pueblos que lo albergaban; pero desgraciadamente todas las matanzas de judíos de la Edad Media no han bastado para hacer este periodo más apacible, no más seguro a los hermanos cristianos [...] Tampoco fue obra de un azar ininteligible el que los hermanos recurtieran al antisemitismo para realizar más completamente su sueño de supremacía mundial. (El subrayado es mio.)

Sabemos, pues, que la cohesión del propio grupo descansa, por una parte, en la defensa de inrereses socioeconómicos y, por otra parte, en esta desconfianza primaria y ancestral hacia el grupo foráneo. De aquí que la sociabilidad más artificial (civilizada) basada en valores universalistas y cosmopolitas se oponga a este otro concepto de sociabilidad más primitivo o instintivo que busca asegurar la vida y la identidad de la tribu a través de sentimientos de superioridad y de exclusión respecto al grupo rival arbitrariamente homogeneizado y caracterizado por diversos estereotipos.

Por otro lado, si concebimos la xenofobia básicamente como un elemento ideológico legitimador de determinados mecanismos de poder $\mathrm{y}$, al mismo tiempo, como un sentimiento reactivo de prevención y de defensa que se da en identidades supuestamente amenazadas por la acción de grupos foráneos, entonces estamos fijando su origen en imágenes y representaciones totalmente subjetivas o en racionalizaciones que tanto si tienen algún punto de contacto con la realidad como si no lo tienen, en cualquier caso, pueden ser reforzadas por factores objetivos y racionales. Me inclino a pensar, pues, que la segregación social de las minorías étnicas ha sido desde siempre producto de las relaciones de poder intergrupales, aunque sus efectos se manifiesten mucho más claramente y con más virulencia cuando se cruzan con intereses materiales en disputa o en tiempos de incertidumbre económica (por ejemplo, el racismo se propaga en algunas partes con extrema rapidez en épocas de crisis, recesión, paro, etc. precisamente porque existían allí de forma larvada o latente las condiciones para que pudiera aflorar).

Asimismo, entiendo el concepto de nación más como una entidad cultural (fruto de una dererminada manera de ver el mundo y las relaciones de los individuos con sus instituciones en el tiempo y el espacio por parte de una comunidad) que como una instancia natural, producto de una serie de condiciones objetivas. Aunque éstas deban existir necesariamente, para poder hablar de nación (lengua, territorio, tradiciones, símbolos y demás códigos diferenciales) no constituyen por sí mismas un requisito suficiente para conformarla. Es

9. Freud, Sigmund (1971). Malaise dans la civilisation. Paris: PUF, p. 68-69. 
imprescindible la presencia de un atributo subjetivo, concretamente de una voluntad política que a partir de la interpretación de un pasado histórico construya un proyecto político proestatalista o antiestatalista (o ni una cosa ni otra, según las circunstancias), pero siempre dispuesto a luchar por el reconocimiento del llamado hecho diferencial ante las naciones rivales que pretendan negárselo.

En este sentido, por la importancia que cobran dichos elementos subjetivos, a mi entender, no sería muy equivocado afirmar que la nación es un invento de los nacionalistas. Hay muchos pueblos con rasgos diferenciales objetivos pero sin ninguna conciencia nacional, ni ninguna vocación estatal que les impide presentarse como naciones, y otros cuyo principal patrimonio es esa conciencia colectiva que, expresada en forma de ideales, tiende a naturalizar lo más subjetivo y espiritual (desde las esencias sagradas de la propia historia hasta la carga ideológica que respalda cualquier opción de autogobierno o de independencia).

En un reciente articulo del filósofo y escritor Pep Subirós ${ }^{10}$ aparece una clara definición de la función del nacionalismo y la idea de nación que subscribo totalmente, dice así:

Todo nacionalismo se forja desde un poder de Estado, o contra ese poder, o hacia ese poder, o al menos hacia una cierta forma de autogobierno. La Nación es la abstracción y la reificación de los sentimientos y de la conciencia de identidad, comunidad y pertenencia de una colectividad espiritualmente organizada en función de cierta estructura estatal de poder, existente o imaginaria. [...] La Nación es siempre un hecho de conciencia y de sentimientos. Lo cual no quiere decir que la Nación sea un mero flatus voci sin importancia. Los valores, los sentimientos y las ideas políticas son importantísimos, y sus reificaciones - como por ejemplo la Nación- aún más.

El sociólogo vasco Alfonso Pérez-Agote ${ }^{11}$ aporta también en la misma línea teórica (por otro lado, desarrollada ampliamente por el antropólogo Ernest Gellner ${ }^{12}$ ) otra esclarecedora definición de nación:

Históricamente, la Nación es una forma de legitimarse un centro de poder ya establecido, al ser ocupado éste por grupos sociales que tienden a sustituir la vinculación política personal por otra impersonal. La Nación es la idea de comunidad (mística de todos los ciudadanos) segregada por el Estado; las funciones centrales de esta idea son: la producción de una sociedad a la medida del Estado, el olvido de la violencia primitiva fundadora (todo Estado emana de una guerra civil) y la anulación de las relaciones fundamentales de significación social de los territorios diferenciales cuya unificación forma el territorio del Estado. [...] Del mayor o menor éxito en la difusión de la idea de Nación por parte del

10. Subirós, P. (1992). "Genealogia del nacionalismo". Claves de razón práctica, núm. 24, julio/agosto, p. 33.

1I. Alfonso Pérez-Agote, de una ponencia titulada Sobre La nación: un inventario de problemas tebricos, que fue presentada en el XII Congreso Mundial de Sociologia. Madrid, 1990.

12. Gellner, Ernest (1988), "Naciones y nacionalismon. Madrid: Alianza. 
Estado dependerá el surgimiento o resurgimiento de nacionalismos periféri$\cos$, de colectivos que lancen la idea de otra Nación contra aquel Estado.

[...] ]o que se inaugura históricamente con la Nación es la proyección política de los sentimientos de comunidad, dada la supresión del vínculo politico de carácter personal. [...] La comunidad es un sentimiento de pertenencia realmente existente y difundido: no basta con que sea definida por algunos desde dentro, es necesario que sea vivida por una gran mayoría.

Como dije anteriormente, los anhelos de satisfacción y de seguridad constituyen principios básicos reguladores de la vida. En este sentido, al igual que la xenofobia, pienso que el nacionalismo en última instancia también persigue la construcción de una identidad colectiva bajo la cual encuentran cobijo estructuras de carácter dependientes y necesitadas de autoafirmación a través de elementos de analogia y diferencia respecto al propio clan y al clan rival, respectivamente.

La ideología nacionalista deviene problemática, por tanto, cuando para mantener su propia razón de ser u otros intereses más espúreos puede llegar a justificar cualquier tipo de segregación xenófoba. La vinculación entre el nacionalismo y un sentimiento de discriminación por razones étnicas, como es el racismo, la expone Etienne Balibar ${ }^{13}$ en los siguientes términos:

Al menos parte de los historiadores han usado esta cuestion para argumentar que el racismo (como discurso teórico y cono fenómeno de masas) se desaxrolla "dentro del campo del nacionalismo" omnipresente en la época moderna. De este modo, el nacionalismo serf́a, si no la causa única del racismo, en cualquier caso la condición determinante para su aparición. Mejor aún: las explicaciones "económicas" (por efecto de la crisis) o "psicológicas" (por la ambivalencia del sentimiento de la identidad personal y de la pertenencia colectiva) sólo serían perrinentes en la medida en que iluminaran presupuestos o efectos provocados por el nacionalismo.

13. Etienne Balibar e Immanuel Wallerstein en el libro Raza, nación y clase (Madrid: IEPALA, 1991) cap. 3, del primero de ellos, titulado "Racismo y nacionalismon, p. 63-64. 